Original Article

\title{
ASSESSMENT OF ANTIMICROBIAL EFFICACY OF KOHL/KAJAL PREPARED BY DIFFERENT INDIAN METHODS AGAINST SELECTED MICROBIAL STRAINS
}

\author{
DHEERAJ S. RANDIVE ${ }^{12 *}$, SOMNATH D. BHINGE2, NAMDEO R. JADHAV3, MANGESH A. BHUTKAR², MRUNAL K. \\ SHIRSAT $^{4}$
}

1Pacific Academy of Higher Education and Research University, Udaipur, Rajasthan, India 313003, ${ }^{2}$ Rajarambapu College of Pharmacy Kasegaon, Walwa, Sangli Maharashtra India 415404, 3Bharati Vidyapeeth College of Pharmacy, Kolhapur, Maharashtra, India 416013, 4Dean and Professor Pacific College of Pharmacy, PAHER University Udaipur 313003

Email: randivedheeraj@gmail.com

Received: 15 Jan 2020, Revised and Accepted: 22 Mar 2020

\begin{abstract}
Objective: To prepare and evaluate different types of Kajal formulations and evaluation of its antimicrobial activity along with preliminary verification of the content responsible for the said effect.

Methods: We have prepared kajal formulations by use of different metal plates, marble tile, ghee and Aloe vera mucilage and tried to verify the antimicrobial effect attributed to the formulation by these substances.

Results: Carbon soot obtained from the use of copper plate showed more antimicrobial potential against Staphylococcus aureus, Pseudomonas aeruginosa and $E$. coli, with zones of inhibition $18 \pm 0.235 \mathrm{~mm}, 17 \pm 0.124 \mathrm{~mm}$ and $19 \pm 0.528 \mathrm{~mm}$ respectively. Also this formulation at different concentrations when compared with Ciprofloxacin exhibited promising results. Moreover, this formulation when used with Ciprofloxacin at a concentration of (50:50) revealed a synergistic effect against the clinically resistant strains of $P$. aeruginosa, with zone of inhibition $22 \pm 0.578$ mm and $20 \pm 0.987 \mathrm{~mm}$ at a concentration of 10 and $5 \mu \mathrm{g} \mathrm{ml}-1$ respectively, whereas, Ciprofloxacin exhibited zone of inhibition of $26 \pm 0.457 \mathrm{~mm}$ and $24 \pm 0.751 \mathrm{~mm}$ at the similar concentrations. To assess the effectiveness of Aloe vera we used marbles tiles for collection of carbon soot. The zones of inhibition observed for Kohl formulations prepared by using carbon soot collected from marble tiles impregnated with Aloe vera mucilage exhibited less antimicrobial activity than that of copper soot against the selected microbial strains.
\end{abstract}

Conclusion: All the prepared kajal formulations exhibited antimicrobial activity. Aloe vera and copper soot is responsible for significant antimicrobial activity and when combined with Ciprofloxacin it showed synergistic activity against the clinically resistant strains of $P$. aeruginosa.

Keywords: Kajal, Carbon soot, Aloe vera, Antimicrobial activity, Synergistic activity

(C) 2020 The Authors. Published by Innovare Academic Sciences Pvt Ltd. This is an open access article under the CC BY license (http://creativecommons.org/licenses/by/4.0/) DOI: http://dx.doi.org/10.22159/ijcpr.2020v12i3.38302. Journal homepage: https://innovareacademics.in/journals/index.php/ijcpr

\section{INTRODUCTION}

Advancement in the Ayurvedic system of medicine has been revolutionized from the screening of phytochemicals, pharmacological activities to elucidating their mechanisms and sites of action [1]. Numerous Ayurvedic products which are available in the market markedly vary in their quality and therapeutic efficacy owing to the differences in their composition. Knowledge about active principles of the herbal preparations are not well defined, information on toxicity and ill effects of these formulations are lacking [2]. Herbal treatments applied topically have gained popularity due to their widespread use and ill-defined benefit/risk ratio [3]. In Ayurveda, Pitta dosha stands for the element of fire and light that governs our eyes.

Eye is the index of our soul and is an unique organ from the anatomical and physiological point of view. Without eye we cannot enjoy the beauty of nature [4]. Eye makeup has long been used to enhance personal appearance, to improve self-esteem or attract the attention of others. Cosmetics used as eyeliners, eye shadow, mascara, eyelash curlers, eye makeup removers...etc could all contribute to eyelid Blepharitis [5]. Vedic science offers several natural, safe and effective techniques to care for the eyes especially for beautification. Amongst which, Kajal, Al-kahal, Kuhl, Soorma, Ithmid are the synonyms of kohl, a cosmetic whose role in eye products cannot be ignored. Kajal is the thick, black ointment preparation, used in the hindu and muslim religious country for the health of eyes as eye liners. Kajal is usually applied with one fingertip on the inner rim of the lower eyelid and on upper lid. It helps to remove the impurities from the eye as well and also keeps the eye cool for a long period of time [6]. It is a traditional powderlike mixture used as eyeliner and to treat eye disease in many
Middle and Far East countries [7]. Traditionally, in many countries, eye kohl is applied to newborn children; parents believe it works against pain and evil eyes [8]. In countries of the Arabian Peninsula, kohl refers to several preparations, including black kohl, which is largely composed of a fine powder of the lead sulfide $(\mathrm{PbS})$ ore galena. As as well Kohl is an ancient eye cosmetic, traditionally made by grinding stibnite (Sb2S3).

[9-12] India is the one of the country which is using the Kajal not only for beautification purpose but also for protection of the eye in woman and children's from ancient time. Lots of different techniques are used in India for the preparation of kajal but most of the techniques have not been well documented in the scientific literature. Using Almond, camphor, aloe vera, castor oil, ghee etc kajal have been prepared in ancient ayurvedic practice along with copper, bronze, silver, gold plate as a soot collecting base [13]. Gupta et al. (2016) formulated herb based kohl containing Almond oil soot, Castor oil, Mentha extract, Ocimum extract, Vitex extract and vegetable ghee etc and claimed their antimicrobial activity. However, the ingredient(s) responsible for the said effect has not been clearly mentioned [10]. Moreover, Sherwal B L et al. (2008) reported different types of microbes responsible for eye infection namely Staphylococcus aureus (19.13\%), Pseudomonas aeruginosa $(4.92 \%)$, and Escherichia coli $(1.10 \%)$ which are still the most common isolates among the known and opportunistic pathogens in ocular infection [14]. Therefore we have selected the aforesaid species for assessment of the antimicrobial activity of the prepared formulations.

Though, Kajal is one of the most important component in eye makeup, but still its medicinal use is bit limited and hence 
formulating a medicated Kajal as a Cosmeceutical product to combat eye infections and beautification was thought of as an innovative approach.

Moreover, nowadays antimicrobial resistance or multidrug resistant is a matter of serious concern. Already numerous microbial species including Pseudomonas aeruginosa have developed resistance to several commonly used antibiotics. Thus, additionally we have studied the developed Kajal formulation from the copper soot for clinically resistant (Multi Drug Resistance) strain of Pseudomonas aeruginosa.

Therefore, the intention of the study was i) to explore the different techniques for the preparation of Kajal formulation in India ii) to assess the comparative antimicrobial activity of prepared Kajal formulation iii) to find the content(s) from the formulation responsible for the antimicrobial activity and iv) to study the efficacy of formulated kajal and standard against the resistant strains of microbial species.

\section{MATERIALS AND METHODS}

Ciprofloxacin was obtained as a gift sample from Okasa Pharma Limited, Satara. Dimethyl sulfoxide, ethanol, nutrient agar were purchased from Loba chem. Ltd, Mumbai, India. The solid media and broth used for microbial culture were procured from Hi-Media Pvt. Limited, Mumbai, India. All the other materials required for the preparation of kajal formulation were obtained from local area near Kasegaon viz. Aloe vera. The all microbial strains and MDR strain of Pseudomonas aeruginosa obtained from Micro bio lab Pune.

\section{Preparation of carbon soot using different metal plates}

Fresh Aloe vera leaf was taken and peeled off with the aid of blunt knife. The mucilage which oozed out from the leaf was properly collected and evenly spread on the surface of different plates such as silver (Ag); bronze (Bz) and copper (Cu) (table 1). Thereafter, Aloe vera mucilage applied $\mathrm{Ag}$; $\mathrm{Bz}$ and $\mathrm{Cu}$ plates were kept in sunlight for few hours to get dry the applied layer of mucilage. A lamp filled with cow ghee with dipped cotton wick was taken and burnt the flame. The all plates were kept on the separate stand for support as shown in fig. 1. Allowed the lamp to burn the plate on which the mucilage was applied, so that the carbon soot gets collected on the plate. It takes up to 3-4 $\mathrm{h}$ for the carbon soot to get collected. The collected carbon soot was scraped off and collected in a box. Three different types of carbon soot collected from three different metals plates namely $\mathrm{Ag}, \mathrm{Bz}$ and $\mathrm{Cu}$ and they were coded as AgCS, BzCS and CuCS respectively.

\section{Preparation of carbon soot by using marble tiles, Ghee, Aloe} vera and peanut oil

Four types of carbon soot were prepared by replacing the metal plate with marble tiles (table 1). The details are described as follows.

Preparation of FGH carbon soot-A lamp filled with cow ghee with dipped cotton wick was taken and burnt the flame. A marble tile was kept on the separate stand for support over the lamp as shown in fig. 2. After 3-4 h, carbon soot gets collected on the marble tile. The collected carbon soot was scrapped off and collected in a box and coded as FGH.

Preparation of FG carbon soot-A lamp filled with peanut oil with dipped cotton wick was taken and burnt the flame. A marble tile was kept on the separate stand for support over the lamp as shown in fig. 2. After 3-4 h, carbon soot gets collected on the marble tile. The collected carbon soot was scrapped off and collected in a box and coded as FG.

Preparation of FGK carbon soot-Fresh Aloe vera leaf was taken and peeled off with the aid of blunt knife. The mucilage which oozed out from the leaf was properly collected and evenly spread on the surface of marble tile and thereafter, marble tile was kept in sunlight for few hours to get dry. A lamp filled with peanut oil with dipped cotton wick was taken and burnt the flame. A marble tile was kept on the separate stand for support over the lamp as shown in fig. 2. After the 3-4 h, carbon soot gets collected on the marble tile. The collected carbon soot was scrapped off and collected in a box and coded as FGK.
Preparation of FGHK carbon soot-Fresh Aloe vera leaf was taken and peeled off with the aid of blunt knife. The mucilage which oozed out from the leaf was properly collected and evenly spread on the surface of marble tile and thereafter, marble tile was kept in sunlight for few hours to get dry. A lamp filled with ghee with dipped cotton wick was taken and burnt the flame. The marble tile was kept on the separate stand for support over the lamp as shown in fig. 2. After the 3-4 h, carbon soot gets collected on the marble tile. The collected carbon soot was scrapped off and collected in a box and coded as FGHK.

\section{Evaluation for antimicrobial activity}

\section{Antimicrobial activity of carbon soot}

AgCS, BzCS, CuCs, FGH, FG, FGK and FGHK were screened for their antimicrobial activity by Diffused Well Agar Method. It was tested on agar nutrient medium against Pseudomonas aeruginosa Staphylococcus aureus and E. coli. The activity was determined by measuring the diameter of zone of inhibition. The test strains of Pseudomonas aeruginosa, Staphylococcus aureus and E. coli were collected from Department of Microbiology, YC College, Karad (415124), Maharashtra, India. The plates were inoculated with test cultures and the wells ( $6 \mathrm{~mm}$ diameter) were made with help of 6 $\mathrm{mm}$ diameter cork borer and the wells were loaded with prepared dilutions (100 $\mathrm{mg} \mathrm{ml}^{-1}$ ) of AgCS, BzCS, CuCS, FGH, FG, FGK and FGHK separate in defined plate. After $24 \mathrm{~h}$ of incubation, the zone of inhibition was determined.

\section{Antimicrobial activity different types of ghee's}

With an intent to assess the Antimicrobial activity of ghee we performed the tests using four different types of ghee collected and they were coded as G1-Deshi cow ghee, G2-Jarshi cow ghee, G3-buffalo ghee and G4-freshly prepared cow ghee and antimicrobial activity was carried out against Pseudomonas aeruginosa, Staphylococcus aureus, E. coli. The results revealed that none of the tested samples showed indication of antimicrobial potential. We have preferred cow ghee as a vehicle in the preparation of Kohl as traditionally in the Indian system of medicine, Ayurveda cow ghee has been prescribed as a remedy for treatment of various diseases and ailments.

\section{Preparation method of Kajal Formulation from collected carbon soot (AgCS, BzCS, CuCS, FGH, FG, FGK and FGHK)}

2 gm of prepared AgCS, BzCS, CuCS, FGH, FG, FGK and FGHK carbon soot were transferred in a small sterilized copper metal container. Then 2 to 3 drops of cow ghee was added in each container. Care was exercised to add adequate cow ghee, which will prevent formation of smudgy and thick/thin carbon based Kajals. The Kajal formulation were prepared from AgCS, BzCS, CuCS, FGH, FG, FGK and FGHK and coded as AgCSKF, BzCSKF, CuCSKF, FGHKF, FGKF, FGKKF and FGHKKF respectively.

\section{Evaluation of formulations (Kajal)}

\section{Physical evaluation}

All the formulations of Kajal were evaluated for physical parameters like color, odor, texture and consistency.

\section{pH determination}

The $\mathrm{pH}$ of the prepared formulations was measured by $\mathrm{pH}$ meter (Systronics digital-DI-707). One gram of kajal sample was weighed and dispersed in $25 \mathrm{ml}$ of DMSO and stored for $120 \mathrm{~min}$. The estimation of $\mathrm{pH}$ of Kajal formulations was recorded thrice and average taken.

\section{Spreadability}

A special apparatus suggested by Mutimer et al., (1956); was designed for determining spreadability of the prepared all Kajal formulations. An excess amount of Kajal samples were sandwiched in glass slides and a $1000 \mathrm{~g}$ weight was placed on slides for $5 \mathrm{~min}$ to compress a Kajal samples to uniform thickness. Weight (50 gm) was added to the pan. The time required to separate the two slides was taken as a measure of spreadability. Lesser the time taken for separation of two slides, better the spreadability. It was calculated by using the formula: 


$$
\mathrm{S}=\mathrm{M} \cdot \mathrm{L} / \mathrm{t}
$$

Where, $\mathrm{M}$ is the weight $(\mathrm{g})$ tied to the upper glass slide; $\mathrm{L}$ is the length $(\mathrm{cm})$ moved on the glass slide and $t$ is time to separate the slide (sec) [15].

\section{Antimicrobial activity of CuCS soot Kajal formulation}

The carbon soot (CuCS) prepared using Aloe vera and ghee along with copper plate as base showed the singnificant activity than other prepared carbon soot (AgCS and BzCS), therefore, the CuCS soot Kajal formulation (CuCSKF) was assesse for the antimicrobial activity by Diffused Well Agar method. It was tested on agar nutrient medium against Pseudomonas aeruginosa and Staphylococcus aureus. The plates were inoculated with test cultures and the wells $16 \mathrm{~mm}$ diameter) were made with help of $6 \mathrm{~mm}$ diameter cork borer and the wells were loaded with prepared dilutions using Dimethyl sulfoxide (DMSO) as solvent $(100 \mathrm{mg} / \mathrm{ml}$ and $300 \mathrm{mg} / \mathrm{ml}$ ) of CuCSKF and standard (Ciprofloxacin) After $24 \mathrm{~h}$ of incubation, the zone of inhibition was determined.

Antimicrobial activity of clinical resistant strain (MDR) of Pseudomonas aeruginosa of mixture of CuCSKF and standard Ciprofloxacin (1:1)

\section{Preparation of the Ciprofloxacin solution}

Solution A and B were prepared by adding 50 and $100 \mathrm{mg}$ of Ciprofloxacin diluted with $10 \mathrm{ml}$ of DMSO solution to yield a final concentration of solution of 5 and $10 \mathrm{mg} \mathrm{ml}^{-1}$ respectively.

\section{Preparation of CuCSKF solution}

Solution C and D were prepared by adding $50 \mathrm{mg}$ and $100 \mathrm{mg}$ of CuCSKF diluted with $10 \mathrm{ml}$ of DMSO solutions to obtain final concentration of 5 and $100 \mathrm{mg} \mathrm{ml}^{-1}$ respectively.

\section{Preparation of combination CuCSKF and antibiotic solutions} (Solution E)

It was prepared by adding equal volume of Solution A and C ( $1 \mathrm{ml}$ each) to get a Solution $\mathrm{C}$ containing $2.5 \mathrm{mg} \mathrm{ml}^{-1}$ of antibiotic and 2.5 $\mathrm{mg} \mathrm{ml}^{-1}$ of CuCSKF.

\section{Preparation of combination CuCSKF and antibiotic solutions} (Solution F)

It was prepared by adding equal volume of Solution B and D (1 ml each) to get a Solution $C$ containing $5 \mathrm{mg} \mathrm{ml}^{-1}$ of antibiotic and $5 \mathrm{mg}$ $\mathrm{ml}^{-1}$ of CuCSKF.

Antimicrobial test of mixture of CuCSKF and standard Ciprofloxacin (50:50) was performed against the clinically resistant strain (MDR) of Pseudomonas aeruginosa by using 5 and $10 \mu \mathrm{g} \mathrm{ml}^{-1}$ concentrations by the same method described above to find out the synergistic effect [16].

\section{RESULTS}

\section{Antimicrobial activity of carbon soot}

From the results of the study it is clearly indicated that $\mathrm{CuCS}$ possess greater antimicrobial potential with zone of inhibition $18 \pm 0.235$ $\mathrm{mm}, 17 \pm 0.124 \mathrm{~mm}$ and $19 \pm 0.528 \mathrm{~mm}$ against the Staphylococcus aureus Pseudomonas aeruginosa and E. coli respectively. While, the BzCS exhibited $16 \pm 0.211 \mathrm{~mm}, 14 \pm 0.331 \mathrm{~mm}$ and $15 \pm 0.326 \mathrm{~mm}$ as zone of inhibition against the Staphylococcus aureus Pseudomonas aeruginosa and E. coli respectively. In case of AgCS the zone of inhibition were found to be $14 \pm 0.311 \mathrm{~mm}, 15 \pm 0.143 \mathrm{~mm}$ and $13 \pm 0.194 \mathrm{~mm}$ against Staphylococcus aureus Pseudomonas aeruginosa and E. coli respectively as shown in table 2 and fig. 3.

To assess the role of Aloe vera and metals in the antimicrobial activity, soot were prepared by replacing the plate with marble tiles which showed less zone of inhibition as compared to soot obtained from the metal plates and Aloe vera as shown in table 2 and fig. 4.

\section{Antimicrobial activity of different types of ghee}

From the values obtained from table 3 and fig. 5 it is clearly revealed that ghee does not exhibit any antimicrobial effect against the selected strains. Thus, its use is only confined as a base or vehicle for the prepared soot.

\section{Physical evaluation of prepared Kajal formulation}

Prepared Kajal/kohl formulations were evaluated for its physical parameters like color, odor, texture and consistency. All kajal formulations showed the similar physical characteristics like black in color, characteristic odor with smooth appearance or texture and all formulations were found to possess semisolid consistency.

\section{pH determination}

The $\mathrm{pH}$ of Kohl prepared by using different methods was determined by using digital $\mathrm{pH}$ meter results are as shown in table 4 .

\section{Spreadability}

All the formulations prepared from carbon soot were found to possess optimum spreadability, in the range of $8.21 \pm 0.2231$ to $11.82 \pm 0.4720$ as shown in table 4 .

\section{Antimicrobial activity of CuCSKF}

The CuCS was showed significant activity than other prepared carbon soot (AgCS, BzCS, FGH, FG, FGK and FGHK), therefore, the Kajal prepared using copper plate (CuCSKF) was assessed for the antimicrobial activity. The zone of inhibition of CuCSKF was noted to be $32 \pm 0.148 \mathrm{~mm}, 34 \pm 0.586 \mathrm{~mm}$ at a concentration of $100 \mathrm{mg} \mathrm{ml}^{-1}$ and $300 \mathrm{mg} \mathrm{ml}^{-1}$, respectively, against Staphylococcus aureus. Whereas, against Pseudomonas aeruginosa, the same formulation at the $100 \mathrm{mg} \mathrm{ml}^{-1}$ and $300 \mathrm{mg} \mathrm{ml}^{-1}$ concentrations exhibited $20 \pm 0.826$ $\mathrm{mm}$ and $39 \pm 0.487 \mathrm{~mm}$ zone of inhibition respectively. The results are presented in table 5 and fig. 6 .

Antimicrobial activity of CuCSKF and standard Ciprofloxacin against the clinical resistant strain (MDR) of Pseudomonas aeruginosa

The mixture of CuCSKF and standard Ciprofloxacin showed synergistic activity against the clinically resistant strain of Pseudomonas aeruginosa, the zone of inhibition was noted to be $22 \pm 0.578 \mathrm{~mm}$ and $26 \pm 0.457 \mathrm{~mm}$ for sample solution containing CuCSKF+Ciprofloxacin (1:1) and plain Ciprofloxacin respectively at concentration $10 \mathrm{mg} \mathrm{ml}^{-1}$ (table 6 and fig. 7).
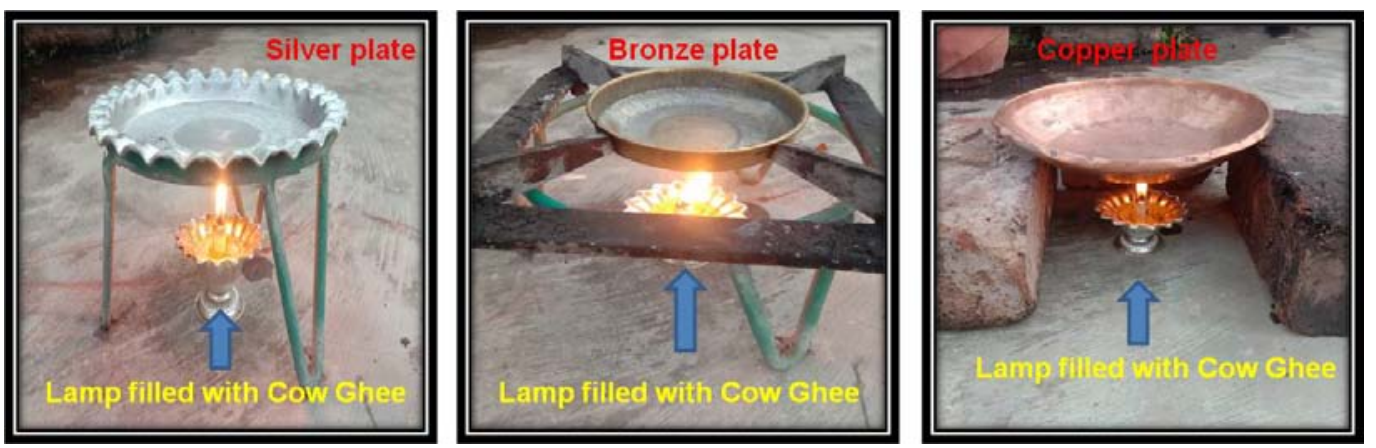

Fig. 1: Preparation of carbon soot by using different metal plates spreaded with Aloe vera mucilage 


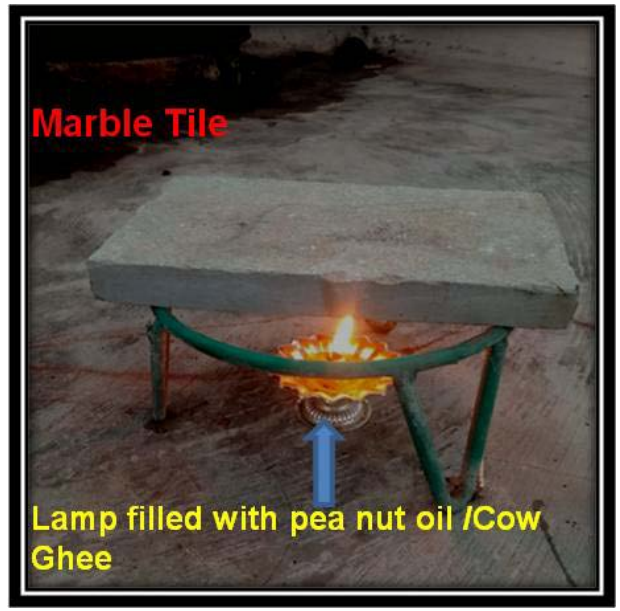

Fig. 2: Preparation of carbon soot by using marble tiles, Aloe vera and Ghee/peanut oil

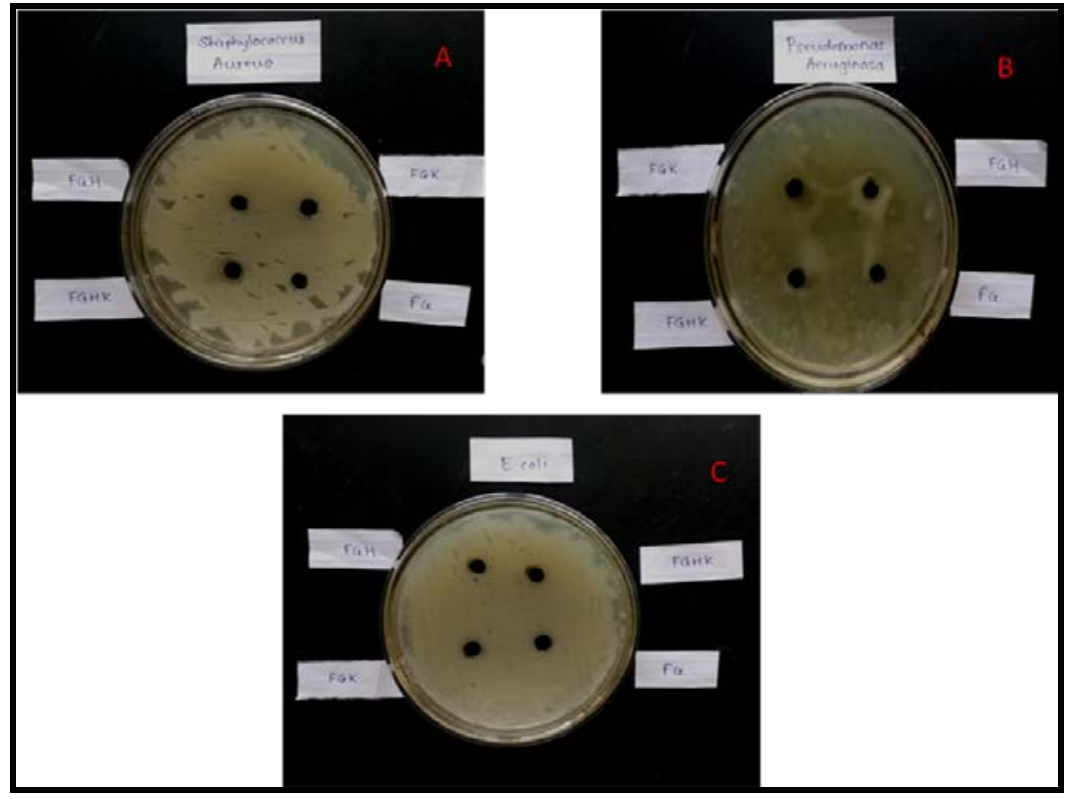

Fig. 3: Zone of inhibition of soot from $\mathrm{Cu}, \mathrm{BZ}$ and Ag against A) Staphylococcus aureus B) Pseudomonas aeruginosa and C) E. coli

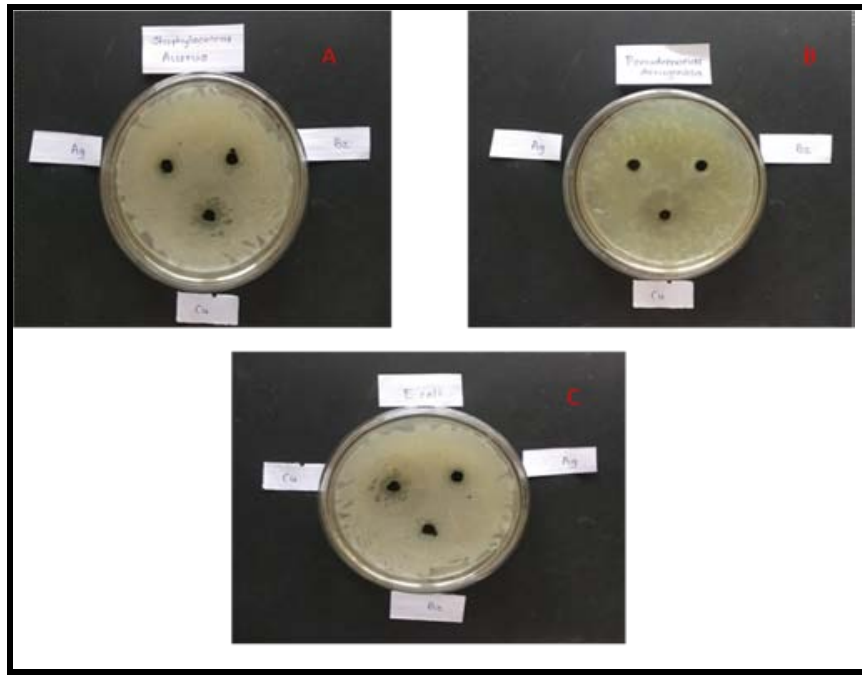

Fig. 4: Zone of inhibition of soot collected from marble tile using ghee, peanut oil and Aloe vera against A) Staphylococcus aureus, B) Pseudomonas aeruginosa and C) E. coli 


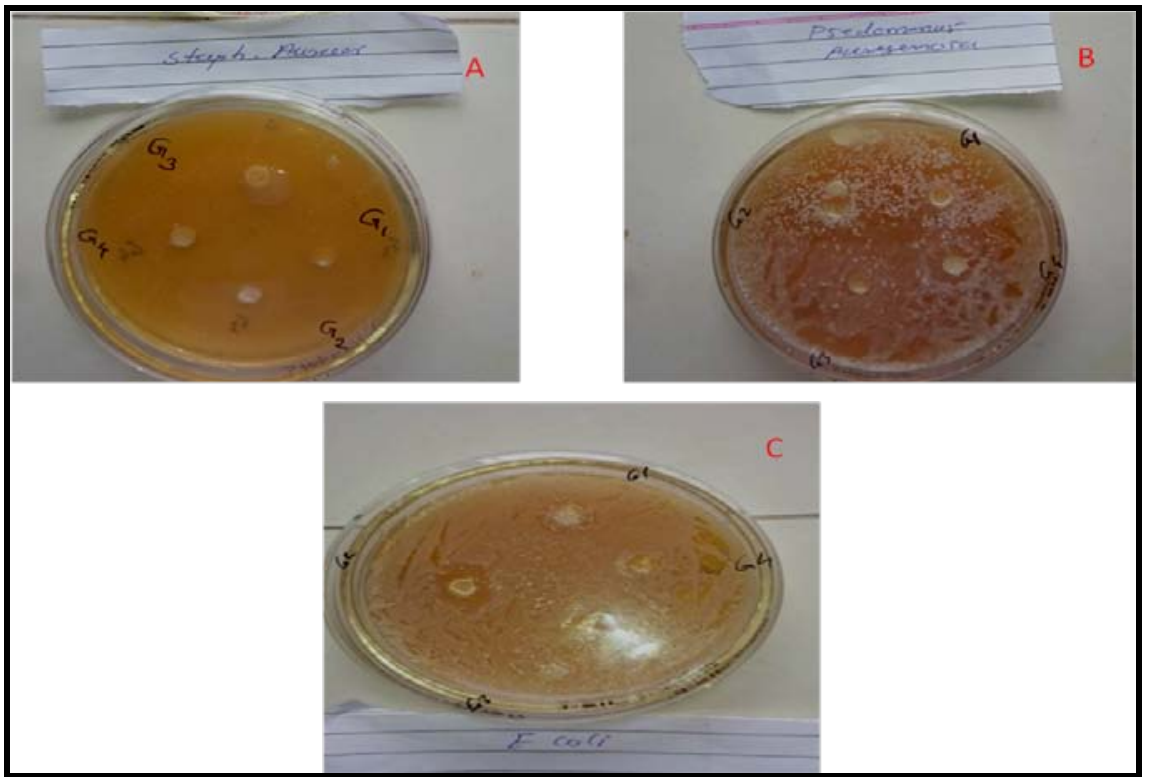

Fig. 5: Zone of inhibition of G1-Deshi cow ghee, G2-Jarshi cow ghee, G3-Buffalo ghee and G4-Freshly prepared cow ghee against A) Staphylococcus aureus, B) Pseudomonas aeruginosa and C) E. coli

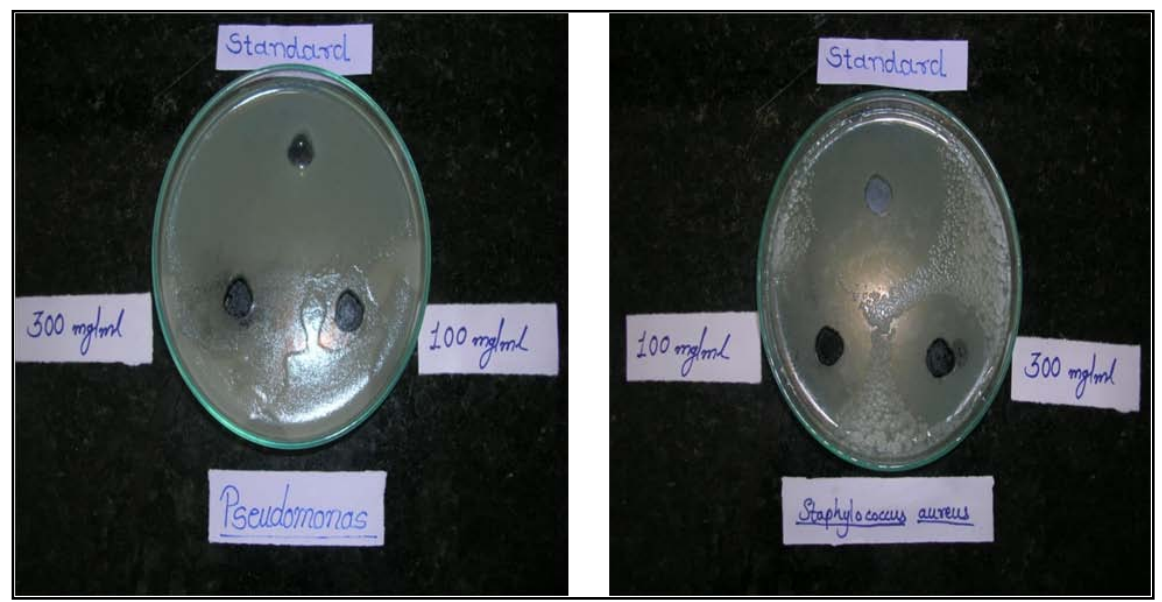

Fig. 6: Zone of inhibition of Soot by using Cu plate $(100 \mathrm{mg} / \mathrm{ml}$ and $300 \mathrm{mg} / \mathrm{ml})$ against Pseudomonas aeruginosa and Staphylococcus aureus with standard Ciprofloxacin

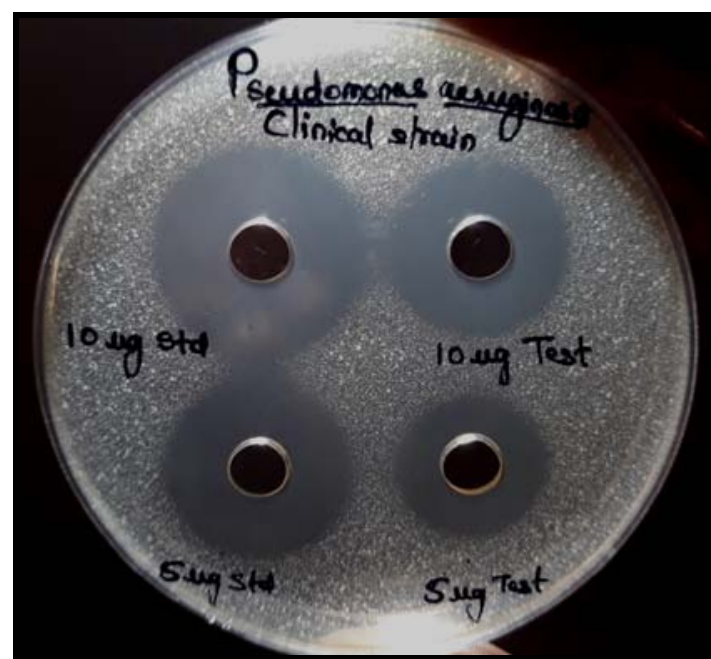

Fig. 7: Zone of inhibition of mixture of soot obtained from Cu plate and Ciprofloxacin (50:50) against clinically resistant (MDR) strain of Pseudomonas aureginosa 
Tables 1: Preparation of carbon soot by using different methods

\begin{tabular}{|c|c|c|c|c|}
\hline S. No. & Material used for soot deposition & Flame containing oil & Plant material & Code \\
\hline 1. & Silver plate & Ghee & Aloe vera gel & AgCS \\
\hline 2. & Bronze plate & Ghee & Aloe vera gel & $\mathrm{BzCS}$ \\
\hline 3. & Copper plate & Ghee & Aloe vera gel & $\mathrm{CuCS}$ \\
\hline 4. & Marble Tiles & Ghee & - & FGH \\
\hline 5. & Marble Tiles & Peanut oil & - & FG \\
\hline 6. & Marble Tiles & Peanut oil & Aloe vera gel & FGK \\
\hline 7. & Marble Tiles & Ghee & Aloe vera gel & FGHK \\
\hline
\end{tabular}

Table 2: Antimicrobial activity results of prepared soot by different methods

\begin{tabular}{llll}
\hline S. No. & Sample name & \multicolumn{2}{l}{ Diameter of zone of inhibition (mm) } \\
\cline { 3 - 4 } & & Staphylococcus aureus & Pseudomonas aeruginosa \\
\hline 1. & CuCS & $18 \pm 0.235$ & $17 \pm 0.124$ \\
2. & BzCS & $16 \pm 0.211$ & $14 \pm 0.331$ \\
3. & AgCS & $14 \pm 0.311$ & $15 \pm 0.143$ \\
4. & FGH & $9 \pm 0.092$ & $8 \pm 0.568$ \\
5. & FG & $8 \pm 0.115$ & $9 \pm 0.482$ \\
6. & FGK & $15 \pm 0.230$ & $14 \pm 0.472$ \\
7. & FGHK & $16 \pm 0.126$ & $15 \pm 0.194$ \\
\end{tabular}

Table 3: Antimicrobial activity of different types of ghee against selected microbes

\begin{tabular}{llll}
\hline S. & Ghee sample & Zone of inhibition (mm) & \\
\cline { 3 - 4 } No. & & Staphylococcus aureus & Pseudomonas aeruginosa \\
\hline 1 & G1-Deshi cow ghee, & $6.0 \pm 0.194$ & $6.4 \pm 0.156$ \\
2 & G2-Jarshi cow ghee, & $6.1 \pm 0.236$ & $6.3 \pm 0.456$ \\
3 & G3-Buffalo ghee & $6.3 \pm 0.167$ & $6.2 \pm 0.582$ \\
4 & G4-Freshly prepared cow ghee & $6.2 \pm 0.569$ & $6.5 \pm 0.429$ \\
\hline
\end{tabular}

Table 4: Results of physical parameters of prepared formulations of kajal

\begin{tabular}{llll}
\hline S. No. & Formulations (Code) & pH & Spreadability \\
\hline 1 & CuCS & $7.06 \pm 0.1247$ & $9.51 \pm 0.2010$ \\
2 & BZCS & $6.90 \pm 0.0816$ & $9.10 \pm 0.4915$ \\
3 & AgCS & $7.06 \pm 0.1247$ & $8.81 \pm 0.3625$ \\
4 & FGH & $7.20 \pm 0.0816$ & $11.82 \pm 0.4720$ \\
5 & FG & $7.71 \pm 0.0816$ & $7.61 \pm 0.5115$ \\
6 & FGK & $7.91 \pm 0.0816$ & $9.19 \pm 0.4351$ \\
7 & FGHK & $6.80 \pm 0.0729$ & $8.21 \pm 0.2231$ \\
\hline
\end{tabular}

Table 5: Antimicrobial activity of CuCSKF Kohl/kajal formulation and standard drug

\begin{tabular}{|c|c|c|c|c|}
\hline \multirow[t]{2}{*}{ S. No. } & \multirow[t]{2}{*}{ Organism name } & \multirow[t]{2}{*}{ Sample name } & \multicolumn{2}{|c|}{ Diameter of zone of inhibition (mm) } \\
\hline & & & $100 \mathrm{mg} / \mathrm{ml}$ & $300 \mathrm{mg} / \mathrm{ml}$ \\
\hline \multirow[t]{2}{*}{1} & Staphylococcus aureus & CuCSKF & $32 \pm 0.148$ & $34 \pm 0.586$ \\
\hline & & Standard (Ciprofloxacin) & $49 \pm 0.953$ & NA \\
\hline \multirow[t]{2}{*}{2} & Pseudomonas aeruginosa & CuCSKF & $20 \pm 0.826$ & $39 \pm 0.487$ \\
\hline & & Standard (Ciprofloxacin) & $45 \pm 0.843$ & NA \\
\hline
\end{tabular}

Table 6: Antimicrobial activity of clinical resistant (MDR) strain of Pseudomonas aeruginosa of Cu soot and standard Ciprofloxacin (50:50)

\begin{tabular}{|c|c|c|c|c|}
\hline \multirow[t]{2}{*}{ S. No. } & \multirow[t]{2}{*}{ Organism name } & \multirow[t]{2}{*}{ Sample name } & \multicolumn{2}{|c|}{ Diameter of zone of inhibition (mm) } \\
\hline & & & $10 \mu \mathrm{g} / \mathrm{ml}$ & $5 \mu \mathrm{g} / \mathrm{ml}$ \\
\hline 1 & Clinical resistant strain (MDR) of Pseudomonas aeruginosa & Standard Ciprofloxacin & $26 \pm 0.457 \mathrm{~mm}$ & $24 \pm 0.751 \mathrm{~mm}$ \\
\hline 2 & & $\begin{array}{l}\text { Sample } \\
\text { CuCSKF+Ciprofloxacin (1:1) }\end{array}$ & $22 \pm 0.578 \mathrm{~mm}$ & $20 \pm 0.987 \mathrm{~mm}$ \\
\hline
\end{tabular}

\section{DISCUSSION}

Kajal has been used for beautifying purposes and also for protection and cure of eye diseases since, ancient civilizations, particularly in Hindu and Muslim religious countries, viz: Rome, India, Egypt, China, Japan, etc. As per Unani, Ayurveda and Greko-Arabica systems of medicine literature etc. eye cosmetics are as old as vanity. Few centuries ago, especially, in the $16^{\text {th }}$ era, the people were using the Kajal for enhancing the appearance of eye. Most of the Hindu and Muslim religious countries have continued use of Kajal formulations till date.

In this study we have prepared kohl/kajal by using different Indian methods to prove the antimicrobial effect of substance like metal plates, ghee and Aloe vera. There are great numbers of medicinal herbs and plants which are widely used in the treatment of diseases and also known to possess antimicrobial activity [17]. Aloe vera 
belonging to family Asphodelaceae has been known to possess varied medicinal properties namely anti-inflammatory, antioxidant, laxative, wound healing, moisturizing, anti-aging, antitumor, anti diabetic, antibacterial, antiviral, antifungal etc. $[18,19]$. Also it is a known protective against the effects of skin exposure to UV and Xradiation. Externally it is used for the treatment of various skin conditions such as cuts, burns and eczema. It has antiseptic and antibiotic properties which make it highly valuable in treating cuts and abrasions [20]. Aloe vera is also used for soothing the skin and keeping the skin moist to help avoid flaky scalp and skin in harsh and dry weather [21].

Ghee is widely considered as the Indian name for clarified butterfat, usually prepared from cow's milk, buffalo milk or mixed milk. [22] The use Cow Ghee has been mentioned in Ayurveda for numerous medical applications, including the treatment of allergy, skin and respiratory diseases. It is also known to retard the undesirable effects of drugs besides cancelling the effect of toxins in the body. However, Cow ghee has to be used in its optimal volume and form in order to increase the efficacy of the Ayurvedic preparations. [23]

From the results, it was found that carbon soot (100 mg ml-1) obtained from the copper $(\mathrm{Cu})$ exhibited more antimicrobial potential with zones of inhibition $18 \pm 0.235 \mathrm{~mm}, 17 \pm 0.124 \mathrm{~mm}$ and $19 \pm 0.528 \mathrm{~mm}$ against the Staphylococcus aureus, Pseudomonas aeruginosa and E. coli respectively.

Moreover, the selected copper soot containing kajal when studied against the aforesaid microbial strains at concentrations $100 \mathrm{mg} \mathrm{ml}^{-1}$ and $300 \mathrm{mg} \mathrm{ml}^{-1}$, zone of inhibitions was found to be $32 \pm 0.148 \mathrm{~mm}$ and $34 \pm 0.586 \mathrm{~mm}$ respectively against the Staphylococcus aureus pathogen. Whereas, the zone of inhibition was noted to be $20 \pm 0.826$ $\mathrm{mm}$ and $39 \pm 0.487 \mathrm{~mm}$ for copper soot containing kajal at concentrations $100 \mathrm{mg} \mathrm{ml}^{-1}$ and $300 \mathrm{mg} \mathrm{ml}^{-1}$ respectively against the Pseudomonas aeruginosa.

Standard Ciprofloxacin showed zone of inhibition $45 \pm 0.843 \mathrm{~mm}$ and $49 \pm 0.953 \mathrm{~mm}$ against Staphylococcus aureus and Pseudomonas aeruginosa respectively at a concentration of $100 \mathrm{mg} \mathrm{ml}^{-1}$.

In the recent years, "antimicrobial resistance" is the serious issue and a matter of concern worldwide. Our formulated Kajal preparation when used with standard (Ciprofloxacin) at a concentration of (50:50) revealed a synergistic effect against the clinically resistant strains (MDR) of Pseudomonas aeruginosa thereby exhibiting zone of inhibition $20 \pm 0.987 \mathrm{~mm}$ and $22 \pm 0.578 \mathrm{~mm}$ at a concentration of $5 \mu \mathrm{g}$ $\mathrm{ml}^{-1}$ and $10 \mu \mathrm{g} \mathrm{ml}^{-1}$ respectively. Whereas, the standard (Ciprofloxacin) exhibited $24 \pm 0.751 \mathrm{~mm}$ and $26 \pm 0.457 \mathrm{~mm}$ as zone of inhibition at the similar concentration respectively.

Further, with an intent to evaluate the effectiveness of Aloe vera we have replaced the metal plates with marbles tile which showed very less antimicrobial potential against the selected microbes, as FGK and FGHK formulation comprising of Aloe vera and Cow ghee showing antimicrobial potential in the range of $8 \pm 0.568 \mathrm{~mm}$ to $16 \pm 0.126 \mathrm{~mm}$ which was less than soot collected from copper plate.

From the above results, the prepared carbon soot showed potential antimicrobial activity against the selected microbes. The said activity is may be due to the use of ghee in prepared soot and kajal, to verify that, we have performed the antimicrobial activity of plain used ghee against the same microbial strain. However it does not showed any zone of inhibition. Henceforth ghee is not responsible to get the aforesaid activity. The significant activity may be attributed due to the use of Aloe vera and copper plate. In addition, we have evaluated all the formulations for their physical characteristics namely color, texture, $\mathrm{pH}$ and spreadability. It does not showed any significant differences.

\section{CONCLUSION}

From the results obtained we have scientifically explored the different methods of preparation of Kajal/kohl for better antimicrobial potential against the microbes like Staphylococcus aureus, Pseudomonas aeruginosa. and E. coli, which are present in the eye infections. We concluded that all prepared kajal formulations exhibited antimicrobial activity. However the formulation prepared from collecting soot deposited on copper plate impregnated Aloe vera using cow ghee flame showed promising antimicrobial activity almost comparable with standard drug Ciprofloxacin. Additionally, synergistic effect was observed against the clinical resistant strain of Pseudomonas aeruginosa when preparation was combined with Ciprofloxacin in the concentration 50:50.

\section{ACKNOWLEDGEMENTS}

The authors are thankful to the Dean P. G. studies Pacific academy of higher education and research university, Udaipur, Rajasthan. We are also thankful to the Secretary KES society Kasegaon, and Principal Rajarambapu College of Pharmacy, Kasegaon, Sangli, Maharashtra, for providing facilities

\section{FUNDING}

Nil

\section{AUTHORS CONTRIBUTIONS}

DSR, MAB, SDB, MKS and NRJ carried out the design, conduct of the study and wrote the manuscript. SDB participated in the data analysis. DSR carried out the data collection.

MKS carried out the design, conduct of the study DSR wrote the manuscript.

All authors read an approved the final manuscript

\section{CONFLICTS OF INTERESTS}

The authors declare that they have no competing interest.

\section{REFERENCES}

1. Randive DS, Bhinge SD, Wadkar GH, Bhutkar MA. Comparative standardization of marketed formulations of fermented biomedicine-arjunaristha. Ind J Pharm 2016;27:220-5.

2. Randive DS, Sayyad SF, Bhinge SD, Bhutkar MA. Preparation of Arjunārișța using microbes isolated from woodfordia fruticosa flowers (dhayati). Anc Sci Life 2016;36:42-7.

3. Bhinge SD, Bhutkar MA, Randive DS, Wadkar GH, Kamble SY, Kalel PD, et al. Formulation and evaluation of polyherbal gel containing extracts of Azadirachta indica, Adhatoda vasica, Piper betle, Ocimum tenuiflorum and Pongamia pinnata. J Res Pharm 2019;23:44-54.

4. Gandhi BM, Shankar PDS. Current trends and challenges faced in ocular drug delivery systems. Int J Res Phar Chem 2012;2:801-5.

5. Hero F, Salah A. Effect of some plant extracts on isolated bacteria from eyelids of natural eye liner users and eye cosmetics users. J Appl Pharm Sci 2012;2:3-8.

6. Mohta A. Kajal (kohl)-a dangerous cosmetic. Omn J Opht 2010;3:100-1.

7. Ali A, Ali AR, Khalid T, Adnan El-Y. Kohl-the traditional eyeliner: use and analysis. Ann Sau Med 1993;13:26-30.

8. Maher MAE, Mohamed AK, Rabia AGH, Daw AM, Mahmud ASA. Chemical and physical investigations of arabian eye kohl brands as cosmetic in Libya. J Tur Chem Soc 2017;4:463-76.

9. Srikanth T, Hussen SS, Anand A, Vasantharaju SG, Sandeep. Der Pharm Lett 2011;3:334-41.

10. Gupta R, Hafsa A, Sehgal S, Dwivedi H. Formulation, preliminary evaluation and antimicrobial activity of a herb based kohl. Int J Phytol Nat In 2016;3:1-5.

11. Sampath Kumar KP, Bhowmik D, Harish G, Duraivel S, Pragathikuma B. Ocular inserts: a novel controlled drug delivery system. Pharm Inn J 2012;12:1-19.

12. Abeer Ali A, Elbanat HM, Solafa AH. Determination of lead concentration in cosmetic (kohl). Sud Uni Sci Tech; 2016. p. 1-28.

13. https://www.boldsky.com/beauty/make-uptips/2017/different-ways-to-make-kajal-athome/articletrending-pf1001-113125.html [Last accessed on 15 Nov 2018]

14. Sherwal BL, Verma AK. Epidemiology of ocular infection due to bacteria and fungus-a prospective study. J Med Ed Res 2008;10:127-31.

15. Mutimer MN, Riffikin C, Hill JA, Marry E, Glickman CNG. Synthesis of methylsilyl derivates of procaine and their diffusion. J Am Pharm Asso Sci 1956;45:212. 
16. Bhinge SD, Bhutkar MA, Randive DS, Wadkar GH, Todkar SS Development and evaluation of antimicrobial polyherbal gel. Annl Pharm Fr 2017;75:349-58.

17. Bhinge SD, Todkar SS, Kakade PM, Kadam PM. Formulation development and evaluation of antimicrobial polyherbal gel. Annl Pharm Fran 2017;75:349-58.

18. Efterpi V, Christaki, Panagiota C, Florou P. Aloe vera: a plant for many uses. J Food Agric Environ 2010;8:245-9.

19. Pankaj KS, Giri DD, Singh R, Pandey P, Gupta S, Shrivastava AK, et al. Therapeutic and medicinal uses of aloe vera: a review. Pharma Pharm 2013;4:599-610.
20. Rajeswari R, Umadevi M, Rahale SC, Pushpa R, Selvavenkadesh S, Sampath Kumar KP, et al. Aloe vera: the miracle plants its medicinal and traditional uses in India. J Pharm Phys 2012;1:118.

21. Sanghi SB. Aloe vera: a medicinal herb. Int J Res Granth 2015;3:32-4

22. Mohammed L, Sserunjogia, Roger K, Abrahamsena JN. A review paper: current knowledge of ghee and related products. Int Dairy J 1998;8:677-88.

23. Mahakalkar A, Kashyap P, Bawankar RH. The versatility of cow ghee-an ayurveda perspective. Am J Drug Delvery Ther 2014;1:28-34. 